\title{
Course and Determinants of Anosognosia in Alzheimer's Disease: A 12-Month Follow-up
}

\author{
Oriol Turró-Garriga ${ }^{\mathrm{a}, \mathrm{b}}$, Josep Garre-Olmo ${ }^{\mathrm{a}, \mathrm{c}, *}$, Laia Calvó-Perxas ${ }^{\mathrm{a}}$, Ramón Reñé-Ramírez ${ }^{\mathrm{d}}$, \\ Jordi Gascón-Bayarrid and Josep Lluís Conde-Sala ${ }^{\mathrm{a}, \mathrm{e}}$ \\ ${ }^{\mathrm{a}}$ Health, Aging and Disability Research Group, Girona Biomedical Research Institute (IDIBGI), Girona, \\ Catalonia-Spain \\ ${ }^{\mathrm{b}}$ Department of Neurology, Institut d'Assistència Sanitária-Institut Catalá de Salut de Girona, Salt, \\ Catalonia-Spain \\ ${ }^{\mathrm{c}}$ Department of Medical Sciences, University of Girona, Girona, Catalonia-Spain \\ ${ }^{\mathrm{d}}$ Dementia Unit, Department of Neurology, Bellvitge University Hospital, Hospitalet de Llobregat, \\ Catalonia-Spain \\ ${ }^{\mathrm{e}}$ Faculty of Psychology, University of Barcelona, Barcelona, Catalonia-Spain
}

Handling Associate Editor: Marcia Dourado

Accepted 4 December 2015

\begin{abstract}
Anosognosia in Alzheimer's disease (AD) has been associated with greater cognitive impairment and more behavioural and psychological symptoms of dementia (BPSD). This study examines the incidence, persistence, and remission rates of anosognosia over a 12-month period, as well as the related risk factors. This was an observational 12-month prospective study. The longitudinal sample comprised 177 patients with mild or moderate AD, and their respective caregivers. Anosognosia was assessed using the Anosognosia Questionnaire in Dementia, and we also evaluated cognitive status (Mini-Mental State Examination), functional disability (Disability Assessment in Dementia), and the presence of BPSD (Neuropsychiatric Inventory). Multinomial logistic regression was used to determine the variables associated with the incidence, persistence and remission of anosognosia. The prevalence of anosognosia was 39.5\% (95\% CI = 32.1-47.1) at baseline. At 12 months, incidence was $38.3 \%(95 \% \mathrm{CI}=28.6-48.0)$, persistence was $80.0 \%(95 \% \mathrm{CI}=69.9-90.1)$ and remission was $20.0 \%$ (95\% CI =9.9-30.1). The regression model identified lower age, more education, and the presence of delusions as variables associated with incidence, and more education, lower instrumental DAD score, and disinhibition as variables associated with persistence. No variables were associated with remission $(n=14)$. The presence of anosognosia in AD patients is high. Education and certain neuropsychiatric symptoms may explain a greater and earlier incidence of anosognosia. However, anosognosia also increases with greater cognitive impairment and disease severity.
\end{abstract}

Keywords: Alzheimer's disease, anosognosia, caregivers, epidemiological dementia study, incidence, insight, dementia, longitudinal studies, neuropsychiatric disorders

\footnotetext{
*Correspondence to: Josep Garre Olmo, Edifici Mancomunitat 1, Parc Hospitalari Martí i Juliá, c/ Dr. Castany s/n 17191 Salt, Girona, Catalonia-Spain. Tel.: +34 6303034241833; Fax: +34 08721116161; E-mail: josep.garre@ias.cat.
}

\section{INTRODUCTION}

The lack of insight regarding one's deficits is commonly referred to as anosognosia, which is defined as a disordered awareness of illness and of its severity and repercussions $[1,2]$. Certain diseases are typically associated with the denial or minimization 
of the deficits associated with them. For example, denial of delusions is common among patients with schizophrenia who have mild cognitive impairment. A similar phenomenon may be observed in some neurological disorders. For instance, patients with hemiplegia following a stroke may deny their inability to move the contralateral extremity, while those with frontotemporal dementia often deny their cognitive impairment, executive dysfunction, and the need for help and supervision [3-6].

Anosognosia is also common in Alzheimer's disease $(\mathrm{AD})$ and is directly linked to cognitive impairment; consequently, in the later stages of the disease it becomes indistinguishable from the consequences of impaired cognition [1,7]. Anosognosic patients with $\mathrm{AD}$ also underestimate their limitations in activities of daily living (ADL), tend not to adopt compensatory strategies, describe themselves as they were before the disease onset, and are more likely to adopt dangerous behaviours [8-10]. In fact, anosognosia in AD is described as a lack of awareness of impairments in ADL or of neuropsychological deficits, and it has been associated with the presence of other behavioural and psychological symptoms of dementia (BPSD) such as apathy, disinhibition, agitation, irritability, or delusions [11, 12]. Various studies have also reported an inverse correlation between anosognosia and depression in dementia, although some authors have only found this relationship in cases of mild depression or dysthymia, while others describe a stronger association with the apathy component of depression $[13,14]$.

Although anosognosia is associated with cognitive impairment, it may also be present in the early stages of the disease (between $25.7 \%$ and $38.5 \%$ of patients with mild dementia present with anosognosia), where it has worse repercussions for both patients and caregivers [7, 15-17]. Currently, however, there is no biological marker or gold standard for detecting anosognosia, and several instruments have been developed $[11,18,19]$. Furthermore, in the context of $\mathrm{AD}$, anosognosia has been defined in a variety of ways, not merely in relation to a lack of awareness of memory impairment but also of behavioural and functional deficits [18]. In AD, the reported prevalence of anosognosia ranges between 3.5\% [19] and more than $50 \%$ of cases [20]. The heterogeneity in the severity of $\mathrm{AD}$ patients and the instrument used to assess anosognosia are two of the main factors contributing to this variability [1].

There are numerous issues still to be addressed by research on anosognosia, including the neuropatho- logical pathways that underlie the phenomenon, the implications that amnesic syndrome has in implicit anosognosia, or the impact of executive dysfunction on the capacity for self-appraisal [21-23]. However, in all patients, whether they suffer from stroke, schizophrenia, or dementia, the consequences of anosognosia are similar, namely poor treatment adherence or denial of the need for treatment, and increased risk of dangerous behaviours. Importantly, anosognosia also impacts on quality of life and implies greater burden on caregivers [17, 19]. Furthermore, the tendency to underestimate symptoms or to ascribe them to mere aging often delays the request for a medical consultation or the provision of well-timed interventions [10].

In the context of research on anosognosia in $\mathrm{AD}$, there are, to the best of our knowledge, no longitudinal studies that provide data regarding its incidence and course. Consequently, the aim of the present study was to identify the factors associated with the course of anosognosia over a 12-month period in patients with mild and mild-to-moderate AD.

\section{METHODS}

\section{Design and study population}

This 12-month prospective observational and analytic study included a convenience sample of outpatients seen at one of two memory clinics in Catalonia (Santa Caterina Hospital in Girona, or Bellvitge University Hospital in Barcelona). They were all diagnosed with $\mathrm{AD}$ according to National Institute of Neurological and Communicative Disorders and Stroke-Alzheimer's Disease and Related Disorders Association criteria [24], scored between 10 and 28 on the Mini-Mental State Exam (MMSE) [25] and their severity was classified as mild or moderate severity according to the Global Deterioration Scale (GDS) [26]. The inclusion criteria included having a main caregiver, defined as the person who was continuously responsible for helping the patient with ADL. In order to exclude the presence of anosognosia due to other medical conditions, the following exclusion criteria were applied: psychosis, history of neurological disorder, vascular or traumatic events, and alcohol or substance dependency or abuse. Patients were also excluded if they had severe communication problems that prevented them from responding adequately to the assessment measures. The study was approved by the hospital's Clinical Research Ethics Committee. 


\section{Procedure}

Neurologists from the memory clinics identified eligible patients according to the inclusion and exclusion criteria and then determined their cognitive function and GDS stage of dementia [26]. Of the total number of patients who met the inclusion criteria, only four families declined to participate. Recruitment took place between January and October 2011. The assessment protocol lasted $90 \mathrm{~min}$ and was administered by trained psychologists and neurologists, both at baseline and at 12 months. Prior to the initial assessment interview, the aims of the study were explained to patients and caregivers, and informed consent was obtained from all participants.

\section{Instruments}

Sociodemographic data (age, gender, education, marital status, and place of residence) for both patients and caregivers were collected by means of a standardized questionnaire. The other aspects assessed were as follows:

\section{Anosognosia}

This was assessed by the Anosognosia Questionnaire-Dementia (AQ-D), an instrument comprising 30 items, each with four possible response options (never, sometimes, often, always). The AQ-D has two forms, one for the patient and one for the caregiver. The total score is obtained by subtracting the scores on the patient's form from those on the caregiver's form, and ranges between 0 and 90 . A discrepancy of more than 32 points $(\geq 1$ standard deviation) indicates the presence of anosognosia [27]. The AQ-D has high internal consistency (Cronbach's alpha $=0.91$ ) and good inter-examiner reliability $(\mathrm{ICC}=0.90)$. Its factor structure comprises two factors, a cognitive-functional factor and a behavioural factor, which explain $38.9 \%$ of the total variance [12].

\section{Cognitive function}

Cognitive impairment was assessed with the MMSE. Scores on the MMSE range from 0 to 30, with a lower score indicating greater cognitive impairment [25].

\section{Functional status}

Specific functional disability was measured using the Disability Assessment in Dementia (DAD). This instrument is administered to caregivers and comprises 40 dichotomous (yes/no) questions that assess the ability of the patient to execute 17 basic activities of daily living (BADL) and 23 instrumental activities of daily living (IADL) [28].

\section{Behavioural and psychological symptoms of dementia}

The Neuropsychiatric Inventory (NPI) is a validated method for assessing the presence of BPSD. It consists of 12 subscales that assess the frequency and severity of delusions, hallucinations, agitation, depression/dysphoria, anxiety, euphoria, apathy, disinhibition, irritability, aberrant motor activity, night-time behavioural disturbances, and appetite and eating abnormalities. The score is the product of the frequency (range $=1-4$ ) and the severity (range $=1-3$ ) of symptoms, and the total score ranges from 0 to 144 points $[29,30]$.

\section{Caregiver burden}

Perceived burden was assessed using the Zarit Burden Interview (ZBI). This is a self-administered test that consists of 22 Likert-type items. Responses reflect the caregiver's perceptions and feelings, and the total score ranges from 22 to 110 points. Higher scores indicate greater perceived burden [31].

\section{Severity of dementia}

The severity of AD was measured by the GDS, which ranges from 1 (no cognitive decline) to 7 (severe cognitive decline). A GDS stage 4 corresponds to cases with mild dementia, GDS 5 and GDS 6 to cases with moderate dementia [26].

\section{Statistical analysis}

A descriptive analysis of the clinical and sociodemographic characteristics of the sample was carried out, using absolute and relative frequencies for qualitative variables and measures of central tendency and dispersion for quantitative variables. The prevalence of anosognosia was established using the relative frequency of each AQ-D group. Changes in anosognosia status groups were determined according to the presence/absence of anosognosia at baseline and at follow-up. Specifically, patients without anosognosia at baseline and presence at 12 months were considered incident cases, those with anosognosia at baseline but an AQ-D score below 32 at 12 months were considered a remission group, patients with anosognosia at both baseline and 12 months were considered persistent cases, and those without anosognosia throughout the study period were 
classified as non-anosognosic patients. The incidence of anosognosia was established using the relative frequency of cases with incident anosognosia at 12-month follow-up. Persistence and remission of anosognosia were established using the AQ-D scores at baseline and at 12-month follow-up. Only cases with both baseline and 12-month follow-up data were considered in the analysis.

Clinical and sociodemographic differences in relation to the presence, incidence, persistence, or remission of anosognosia were analysed by means of parametric and non-parametric tests, in accordance with criteria of normality. When there was a significant difference between two measures, Cohen's (d) was calculated to determine the effect size.

A multinomial logistic regression model was then applied to identify the variables that could predict the incidence, persistence and remission of anosognosia after 12 months, using sociodemographic and clinical characteristics as covariables.

Results were expressed as absolute numbers, percentages, means, standard deviations, and 95\% confidence intervals (CIs). The level of statistical significance was set at 0.05 to test hypotheses. All data processing and analysis was performed using SPSS v17.0 for Windows.

\section{RESULTS}

The baseline sample consisted of 243 patients, of whom 177 (72.8\%) were re-assessed at 12 months. The reasons for drop-out were increased dementia severity or comorbidities (42.4\%), caregiver-related problems (e.g., not present at patient's main residence, work commitments; $16.7 \%$ ), death of patient $(9.1 \%)$, and other causes $(31.8 \%)$. The mean age at baseline of cases which completed the followup was 77.8 years $(\mathrm{SD}=6.5)$; of these, $66.1 \%$ were women and $85.3 \%$ lived in their own home. At baseline, $62.7 \%$ of patients $(n=111)$ were diagnosed with mild dementia (GDS 4). Regarding caregivers, $46.9 \%$ were the spouse and $48.6 \%$ a son or daughter of the patient. The mean age of caregivers was 61.9 years $(\mathrm{SD}=13.2)$, and the majority $(67.2 \%)$ were women.

\section{Anosognosia scores}

The mean score on the AQ-D at baseline was 26.7 $(\mathrm{SD}=18.3)$, rising to $32.4(\mathrm{SD}=18.7)$ at 12 months $\left(\chi^{2}=19.6 ; \mathrm{df}=1 ; p=0.023\right)$. In terms of the severity of dementia, $27.0 \%$ of mild cases (GDS 4) presented anosognosia at baseline (95\% CI 18.3-35.7), as com- pared with $55.2 \%$ (95\% CI 41.5-58.8) of patients with moderate dementia. Table 1 shows baseline clinical and sociodemographic characteristics of patients and caregivers according to the presence or absence of anosognosia.

There were differences between patients' and caregivers' AQ-D scores, and the change in these scores over time also differed. Specifically, while patient perceptions had not changed at 12 months (24.9 at baseline versus 25.5 at 12 months; $Z=-0.649$; $p=0.516)$, caregiver scores increased from 51.6 to $58.0(Z=-6.5 ; p<0.001)$.

\section{Course of anosognosia over 12 months}

The cumulative incidence rate at 12 months was $38.3 \%$ (95\% $\mathrm{CI}=28.6-48.0)$, the remission rate was $20.0 \%(95 \% \mathrm{CI}=9.9-30.1 \%)$ and the persistence rate over 12 months was $80.0 \%$ (95\% CI=69.9-90.1). The incidence among moderate and mild cases was 42.3\% and $37.0 \%$, respectively.

Differences in clinical measures were observed between baseline and the 12-month follow-up. The mean score on the MMSE fell by 1.6 points $(\mathrm{SD}=3.6$; $z=-5.4 ; p<0.001)$, while the mean DAD score was 3.4 points lower at 12 months $(\mathrm{SD}=9.5 ; z=-6.0$; $p<0.001)$. Although the overall score on the NPI did not change significantly during the follow-up period $(z=1.2 ; p=0.208)$, a significant difference was observed on three of its subscales: delusions $(z=-2.8$; $p=0.006)$, apathy $(z=-2.3 ; p=0.017)$, and appetite and eating abnormalities $(z=-3.4 ; p=0.001)$. Table 2 shows the baseline characteristics of patients and caregivers according to the classification of cases at 12 months. In terms of sociodemographic characteristics, incident cases were significantly younger than patients with no anosognosia (Cohen's $d=0.48$ ). Comparison of the clinical characteristics of the change in anosognosia status groups (i.e., incidence, persistence and remission) revealed no significant differences in their baseline MMSE score (KruskalWallis $=1.8 ; \mathrm{df}=2 ; p=0.402$ ). However, a trend was observed across these three groups for functional disability (DAD) and the presence of BPSD (NPI), with greater functional deterioration being observed for activities of daily living, both BADL (Kruskal-Wallis $=18.8 ; \mathrm{df}=2 ; p<0.001)$ and IADL (Kruskal-Wallis $=21.5 ; \mathrm{df}=2 ; p<0.001$ ). The comparative data recorded at baseline and at 12 month follow-up, stratified according to incidence, persistence and remission, are presented in Supplementary Table 1. 
Table 1

Comparison of patient and caregiver clinical and sociodemographic characteristics according to the presence or absence of anosognosia at baseline

\begin{tabular}{|c|c|c|c|c|}
\hline & $\begin{array}{c}\text { No Anosognosia } \\
n=107(60.5 \%)\end{array}$ & $\begin{array}{c}\text { Anosognosia } \\
n=70(39.5 \%)\end{array}$ & $\mathrm{p}$ & $d$ \\
\hline Age of patient, mean (SD) & $76.8(6.7)$ & $79.3(6.0)$ & 0.016 & 0.39 \\
\hline Gender of patient (female), $\mathrm{n}(\%)$ & $76(71.0)$ & $41(58.6)$ & 0.087 & - \\
\hline Education, $\mathrm{n}(\%)$ & & & 0.858 & - \\
\hline Low & $32(29.9)$ & $22(31.4)$ & & \\
\hline Elementary & $65(60.7)$ & $40(57.1)$ & & \\
\hline High & $10(9.3)$ & $8(11.4)$ & & \\
\hline GDS, n (\%) & & & $<0.001$ & 0.70 \\
\hline 4 & $81(73.0)$ & $30(27.0)$ & & \\
\hline $5-6$ & $26(39.4)$ & $40(60.6)$ & & \\
\hline MMSE, mean (SD) & $19.4(4.3)$ & $18.4(5.1)$ & 0.245 & - \\
\hline NPI, n $(\%)$ & $13.1(11.3)$ & $28.1(20.4)$ & $<0.001$ & 0.91 \\
\hline Delusions & $0.6(2.2)$ & $1.1(2.4)$ & 0.139 & - \\
\hline Hallucinations & $0.2(1.2)$ & $0.6(2.0)$ & 0.056 & - \\
\hline Agitation & $1.1(2.6)$ & $2.4(3.2)$ & 0.001 & 0.45 \\
\hline Depression & $1.8(2.5)$ & $2.4(3.2)$ & 0.214 & - \\
\hline Anxiety & $1.4(2.4)$ & $1.8(3.2)$ & 0.790 & - \\
\hline Euphoria & $0.2(0.9)$ & $0.8(2.2)$ & $<0.001$ & 0.36 \\
\hline Apathy & $3.0(3.8)$ & $5.7(4.1)$ & $<0.001$ & 0.68 \\
\hline Disinhibition & $0.3(0.9)$ & $1.8(3.1)$ & $<0.001$ & 0.66 \\
\hline Irritability & $2.0(3.1)$ & $3.9(3.8)$ & $<0.001$ & 0.55 \\
\hline Aberrant motor disorders & $0.5(1.7)$ & $2.9(4.1)$ & $<0.001$ & 0.76 \\
\hline Sleep disorders & $0.5(1.7)$ & $1.3(3.1)$ & 0.055 & - \\
\hline Appetite/Eating & $1.3(2.7)$ & $3.3(3.9)$ & $<0.001$ & 0.60 \\
\hline $\mathrm{DAD}$, mean $(\mathrm{SD})$ & $64.3(9.4)$ & $57.0(8.7)$ & $<0.001$ & 0.81 \\
\hline Age of caregiver, mean (SD) & $60.3(13.4)$ & $64.4(12.7)$ & 0.054 & - \\
\hline Gender of caregiver (female), $\mathrm{n}(\%)$ & $66(61.7)$ & $53(75.7)$ & 0.052 & - \\
\hline $\mathrm{ZBI}, \mathrm{n}(\%)$ & $34.0(16.0 \%)$ & $47.7(16.7 \%)$ & $<0.001$ & 0.83 \\
\hline
\end{tabular}

GDS, Global Deterioration Scale; MMSE, Mini-Mental State Examination; NPI, Neuropsychiatric Inventory; DAD, Disability Assessment in Dementia; ZBI, Zarit Burden Interview.

\section{Risk factors associated with the course of anosognosia}

A binary multinomial logistic regression model was fitted in order to determine the variables associated with incidence, persistence, or remission of anosognosia after 12 months, using absence of anosognosia as the reference group. The results are shown in Table 3, and the model has high goodnessof-fit $($ Cox \& Snell $=0.419 ;$ Nagelkerke $=0.524)$ and a good likelihood ratio $\left(\chi^{2}=119.2 ; \mathrm{df}=15\right.$; $p<0.001)$. Age, education and delusions were found to be predictor variables for incident anosognosia, while education, DAD instrumental score, and disinhibition were associated with the persistence of anosognosia.

\section{DISCUSSION}

The main aims of this study were to determine cumulative incidence, persistence, and remission rates of anosognosia at 12 months, and to identify variables that could predict the course of anosognosia at baseline.

Although a few studies offer longitudinal data on the course of anosognosia, their primary aim was not to study the epidemiology of anosognosia. The lack of a gold standard for defining and detecting anosognosia has led to several different instruments being developed to assess it $[17,32,33]$, and this makes it difficult to compare our results with previous studies. Starkstein et al. also used the AQ-D in a longitudinal study and reported an accumulated incidence rate much lower than ours (21\% versus $38 \%$ ) [34]. Our higher incidence may be due to the fact that our sample contains more patients with moderate-severe and severe dementia, while the sample of Starkstein et al. included a higher proportion of patients with mild dementia, and even patients with mild cognitive impairment. Furthermore, in our study we analysed probable $\mathrm{AD}$ patients, whereas other studies included mixed dementia patients in the analysis and obtained certain differences in their results [35].

Incident cases were younger and had a higher education level than did those cases that remained 
Table 2

Clinical and sociodemographic characteristics of patients and caregivers at baseline, stratified according to the classification of cases at 12 months

\begin{tabular}{|c|c|c|c|c|}
\hline & \multicolumn{4}{|c|}{ Baseline scores } \\
\hline & $\begin{array}{c}\text { No anosognosia } \\
\mathrm{n}=66(37.3 \%)\end{array}$ & $\begin{array}{c}\text { Incidence } \\
n=41(23.2 \%)\end{array}$ & $\begin{array}{c}\text { Persistence } \\
n=56(31.6 \%)\end{array}$ & $\begin{array}{c}\text { Remission } \\
n=14(7.9 \%)\end{array}$ \\
\hline Age of patient*, mean (SD) & $78.0(5.9)^{\mathrm{a}}$ & $74.8(7.4)^{\mathrm{d}}$ & $79.6(6.0)$ & $78.1(5.8)$ \\
\hline Gender of patient (female), $\mathrm{n}(\%)$ & $51(77.3)$ & $25(61.0)$ & $33(58.9)$ & $8(57.1)$ \\
\hline \multicolumn{5}{|l|}{ Education, $\mathrm{n}(\%)$} \\
\hline Low & $25(37.9)$ & $7(17.1)$ & $16(28.6)$ & $6(42.9)$ \\
\hline Elementary & $37(56.1)$ & $28(68.3)$ & $34(60.7)$ & $6(42.9)$ \\
\hline High & $4(6.1)$ & $6(14.6)$ & $6(10.7)$ & $2(14.3)$ \\
\hline \multicolumn{5}{|l|}{ GDS, n $(\%)$} \\
\hline 4 & $51(77.3)$ & $30(73.2)$ & $22(39.3)$ & $8(57.1)$ \\
\hline $5-6$ & $15(22.7)$ & $11(26.8)$ & $34(60.7)$ & $6(42.9)$ \\
\hline MMSE, mean (SD) & $19.5(4.3)$ & $19.2(4.4)$ & $18.6(5.3)$ & $17.4(4.1)$ \\
\hline $\mathrm{NPI}^{*}$, mean $(\mathrm{SD})$ & $12.9(12.7)^{\mathrm{b}}$ & $13.3(8.7)^{\mathrm{d}}$ & $30.4(21.4)$ & $18.9(12.4)^{\mathrm{f}}$ \\
\hline Delusions* & $0.3(1.5)^{\mathrm{b}}$ & $1.2(2.9)$ & $1.4(2.6)$ & $0.1(0.3)$ \\
\hline Hallucinations & $0.2(1.1)^{\mathrm{b}}$ & $0.3(1.3)$ & $0.8(2.2)$ & $0.1(0.3)$ \\
\hline Agitation* & $1.0(2.5)^{\mathrm{b}}$ & $1.4(2.5)$ & $2.6(3.5)$ & $1.5(2.4)$ \\
\hline Depression & $1.9(2.5)$ & $1.5(2.4)$ & $2.4(3.2)$ & $2.4(3.0)$ \\
\hline Anxiety & $1.7(2.7)$ & $1.0(1.8)$ & $2.1(3.5)$ & $0.8(1.3)$ \\
\hline Euphoria* & $0.1(0.7)^{\mathrm{b}}$ & $0.2(1.3)$ & $1.0(2.4)$ & $0(0.0)^{\mathrm{f}}$ \\
\hline Apathy* & $3.0(3.9)^{\mathrm{b}, \mathrm{c}}$ & $3.1(3.6)^{\mathrm{d}}$ & $5.7(4.2)^{\mathrm{e}}$ & $5.4(3.4)$ \\
\hline Disinhibition* & $0.3(1.0)^{\mathrm{b}}$ & $0.3(0.9)^{\mathrm{d}}$ & $2.1(3.0)$ & $0.9(3.2)^{\mathrm{f}}$ \\
\hline Irritability* & $2.0(3.3)^{\mathrm{b}}$ & $2.1(2.6)^{\mathrm{d}}$ & $4.2(4.0)$ & $2.6(2.7)$ \\
\hline Aberrant motor disorders* & $0.5(1.8)^{\mathrm{b}}$ & $0.6(1.6)^{\mathrm{d}}$ & $3.1(4.2)$ & $1.9(3.3)$ \\
\hline Sleep disorders & $0.8(2.1)$ & $0.2(0.7)^{\mathrm{d}}$ & $1.5(3.2)$ & $0.8(2.2)$ \\
\hline Appetite/Eating* & $1.2(2.5)^{\mathrm{b}}$ & $1.5(2.8)^{\mathrm{d}}$ & $3.5(4.1)^{\mathrm{e}}$ & $2.6(3.3)$ \\
\hline $\mathrm{DAD}^{*}$, mean $(\mathrm{SD})$ & $65.1(9.4)^{\mathrm{b}}$ & $63.0(9.3)$ & $56.1(8.6)$ & $60.5(7.8)$ \\
\hline Age of caregiver*, mean (SD) & $59.3(13.4)^{\mathrm{c}}$ & $61.9(13.2)$ & $63.4(13.2)$ & $68.3(10.4)$ \\
\hline Gender of caregiver (female), $\mathrm{n}(\%)$ & $39(59.1)^{\mathrm{a}}$ & $27(65.9)$ & $43(76.8)$ & $10(71.4)$ \\
\hline $\mathrm{ZBI}$, mean (SD) & $32,3(17,0)^{\mathrm{b}}$ & $36,8(14,1)^{\mathrm{d}}$ & $50,0(16,5)$ & $38,8(15,1)$ \\
\hline
\end{tabular}

*Kruskal-Wallis test $p<0.05$; ${ }^{\mathrm{a}}$ Mann-Whitney $\mathrm{U}$ test (no anosognosia versus incidence) $p<0.05$; ${ }^{\mathrm{b}}$ Mann-Whitney U test (no anosognosia versus persistence) $p<0.05 .{ }^{\mathrm{c}}$ Mann-Whitney $\mathrm{U}$ test (no anosognosia versus remission) $p<0.05 ;{ }^{\mathrm{d}}$ Mann-Whitney U test (incidence versus persistence) $p<0.05 ;{ }^{\mathrm{e}} \mathrm{Mann}-\mathrm{Whitney} \mathrm{U}$ test (incidence versus remission) $p<0.05 ;{ }^{\mathrm{f}}$ Mann-Whitney $\mathrm{U}$ test (persistence versus remission) $p<0.05$. GDS, Global Deterioration Scale; MMSE, Mini-Mental State Examination; NPI, Neuropsychiatric Inventory; DAD, Disability Assessment in Dementia; ZBI, Zarit Burden Interview.

without anosognosia at 12 months. In addition, incident cases presented not only a more pronounced decrease in both cognitive and functional performance than did the other cases, but also an increase in the frequency and severity of BPSD (mainly delusions). This rapid evolution is characteristic of patients with higher cognitive reserve [36]. Although cognitive reserve is usually related with less anosognosia [37, 38], our focus here was on the course of anosognosia, not simply its presence or absence at baseline. This means that cases with greater cognitive reserve did not present anosognosia at baseline, even though their pathophysiology could be representative of the persistent group. It should also be noted that incident cases may have an early alteration of the frontal lobe. A sharp decline in cognitive and functional performance has previously been described in patients with a high education level and increased cognitive reserve [39]. In addition, an increased fre- quency and severity of delusions in young patients would fit with a frontal pattern, and neuroimaging studies have already associated anosognosia with a hypoperfusion of the orbitomedial prefrontal cortex [40-42], which occurs in cases with frontotemporal dementia (FTD) too. FTD is usually seen in younger patients, and anosognosia is one of the clinical criteria for diagnosis [40].

Severity of dementia is the main determinant of anosognosia [23], and it was also the factor that best discriminated between persistent and nonanosognosia cases in our study. Persistent cases, which accounted for $80 \%$ of cases with anosognosia at baseline, showed increased disability in IADL and more frequent and severe BPSD, notably disinhibition and apathy. Anosognosia and apathy have been reported by many studies to show a strong inter-relationship [12, 19, 34], and Starkstein et al. concluded that anosognosia is a significant predictor 
Table 3

Forward multinomial logistic regression model for anosognosia status at 12 months

\begin{tabular}{|c|c|c|c|c|c|}
\hline \multirow{2}{*}{$\begin{array}{l}\text { Incidence } \\
\text { Age of patient }\end{array}$} & \multirow{2}{*}{$\frac{\text { B }}{-0.098}$} & \multirow{2}{*}{$\begin{array}{c}\text { OR } \\
0.907\end{array}$} & \multirow{2}{*}{$\begin{array}{c}p \\
0.006\end{array}$} & \multicolumn{2}{|c|}{$95 \% \mathrm{CI}$} \\
\hline & & & & 0.846 & 0.972 \\
\hline Education & 1.184 & 3.267 & 0.003 & 1.508 & 7.076 \\
\hline DAD-instrumental & -0.072 & 0.931 & 0.114 & 0.851 & 1.017 \\
\hline BI & 0.024 & 1.024 & 0.130 & 0.993 & 1.055 \\
\hline NPI disinhibition & -0.167 & 0.846 & 0.454 & 0.546 & 1.310 \\
\hline NPI delusions & 0.361 & 1.435 & 0.015 & 1.071 & 1.923 \\
\hline \multicolumn{6}{|l|}{ Persistence } \\
\hline Age of patient & -0.17 & 0.983 & 0.669 & 0.909 & 1.063 \\
\hline Education & 1.425 & 4.158 & 0.002 & 1.684 & 10.266 \\
\hline DAD-instrumental & -0.290 & 0.749 & $<0.001$ & 0.671 & 0.835 \\
\hline $\mathrm{BI}$ & 0.084 & 1.084 & $<0.001$ & 1.050 & 1.127 \\
\hline NPI disinhibition & 0.344 & 1.410 & 0.015 & 1.070 & 1.859 \\
\hline NPI delusions & 0.213 & 1.237 & 0.143 & 0.930 & 1.645 \\
\hline \multicolumn{6}{|l|}{ Remission } \\
\hline Age of patient & -0.018 & 0.983 & 0.733 & 0.888 & 1.087 \\
\hline Education & 0.434 & 1.543 & 0.443 & 0.510 & 4.670 \\
\hline DAD-instrumental & -0.163 & 0.850 & 0.011 & 0.750 & 0.963 \\
\hline ZBI & 0.042 & 1.043 & 0.043 & 1.001 & 1.087 \\
\hline NPI disinhibition & 0.199 & 1.220 & 0.244 & 0.873 & 1.704 \\
\hline NPI delusions & -0.596 & 0.551 & 0.410 & 0.133 & 2.276 \\
\hline
\end{tabular}

B, beta; OR, odds ratio; DAD, Disability Assessment in Dementia; NPI, Neuropsychiatric Inventory; ZBI, Zarit Burden Interview. Reference category, No anosognosia.

of apathy in AD [34]. Here, we observed an increased rating of apathy in both persistent and incident patients, a finding that is consistent with previous results [34]. Some studies have also demonstrated a common pathogenesis between anosognosia and apathy, linking the evolution of both [22, 23, 41, 42]. Likewise, several authors have described an inverse relationship between affective symptoms and anosognosia $[13,14,19,20,43]$. Assessing the presence of anosognosia could therefore help in differentiating symptoms of depression and apathy and in predicting apathetic symptoms and greater severity.

Remission of anosognosia was only observed in 14 of our patients. Obviously, this small sample offers low statistical power in terms of reliability, and incorrect baseline classification of these patients cannot be ruled out. It should also be taken into account that if anosognosia increases in line with impairment, the AQ-D may have a floor effect when it comes to detecting anosognosia in patients with moderate or moderate-to-severe dementia. These results are consistent with the hypothesis of the "petrified self" proposed by Mograbi and Morris, who attributed unawareness to the process of memory impairment [44]. In this regard, it should be noted that the mean AQ-D score of our patients remained stable (very low) over the 12-month period, whereas caregiver ratings were more negative at follow-up. A further point to consider is that AQ-D scores are based on a patient-caregiver discrepancy, and therefore factors associated with caregiver perceptions should also be considered. Other authors have pointed out that instruments based on discrepancies between patients and caregivers may yield biased results, due to the effect of caregiver burden and emotional stress [45]. That said, in a previous study we found that caregiver burden had a minimal effect on the variability of the AQ-D [46].

Anosognosia is a complex problem that is influenced by factors ranging from the mere anatomical to the broader psychological and social spheres. Moreover, the results of the large population-based study conducted by Mograbi and Morris suggested that memory impairments or the resulting selfstructure were unlikely to provide a full explanation for unawareness in AD. Consequently, the authors concluded that unawareness was associated with different aspects such as depression, dementia severity, education and socioeconomic level in different cultures [47]. Assessing the course of anosognosia might reveal this specificity across international regions, and thus unawareness should be seen not only as a common neurobiological feature of dementia, one that increases with severity of dementia, but also as a phenomenon influenced by social and cultural factors [48]. In this regard, it would be interesting to develop new instruments that could account for most of this variability. 
The main limitations of the present study are those common to all research on anosognosia and relate to the intrinsic limitations of the instrument used to assess anosognosia and the lack of an operational definition of the phenomenon. As we noted earlier, anosognosia may be interpreted in various ways, as affecting cognitive, functional, and/or behavioural aspects of the patient, and this variation is likely to influence the results of its assessment $[1,18,30]$. Other specific limitations related to our study sample should also be taken into account when interpreting the results obtained. The sample comprised patients seen consecutively at our neurology department, whether for the purposes of diagnosis, symptom management, or a routine visit, and all those included were community dwellers. It is possible, therefore, that different results would have been obtained had we included patients living in residential care. It should also be noted that our sample includes moderate patients and eight moderate-to-severe cases, which increased the number of anosognosia patients across the study period. However, the degenerative process may make it impossible to distinguish anosognosia from cognitive impairment, and the AQ$D$ might not be specific enough with these kinds of patients. The education level of our sample was also low, which has an effect on cognitive reserve and may prevent some comparisons with other studies.

Finally, almost two of every five patients in our sample presented with anosognosia at baseline. Younger age, higher education level, and the presence of delusions were the main predictors for incident anosognosia, while higher education level, worse IADL, and disinhibition were associated with persistence. These data provide a platform for future research, since the presence of anosognosia is a factor to consider in new treatment studies using perceived quality of life and self-related pain as the dependent variable. The number of remitted cases in our study was small and prevents us from drawing firm conclusions, and this is another important issue that requires further research. The importance for clinicians of assessing anosognosia is that it could help to differentiate depressive and apathetic symptoms and to predict greater severity. For instance, anosognosia assessment could help to avoid not only a lack of treatment adherence but also risky behaviours related to driving or financial management [10]. These results are also relevant to the needs of caregivers of patients with $\mathrm{AD}$, since anosognosia is known to be one of the key factors leading to greater burden.

\section{ACKNOWLEDGMENTS}

This study was partially conducted within the framework of the project: Assessing perceptions of patient quality of life in patients with Alzheimer's disease and their family caregivers over a two-year period, funded by Spain's Ministry of Economy and Competitiveness (reference PSI2010-19014).

Authors' disclosures available online (http://j-alz. com/manuscript-disclosures/15-0706r1).

\section{SUPPLEMENTARY MATERIAL}

The supplementary material is available in the electronic version of this article: http://dx.doi. org/10.3233/JAD-150706.

\section{REFERENCES}

[1] Leicht H, Berwig M, Gertz HJ (2010) Anosognosia in Alzheimer's disease: The role of impairment levels in assessment of insight across domains. J Int Neuropsychol Soc 16, 463-447.

[2] Clare, L (2004) The construction of awareness in early-stage Alzheimer's disease: A review of concepts and models. $\mathrm{Br}$ $J$ Clin Psychol 43, 155-175.

[3] Orfei MD, Varsi AE, Blundo C, Celia E, Casinni AR, Caltagirone C, Spalletta G (2010) Anosognosia in mild cognitive impairment and mild Alzheimer's disease: Frequency and neuropsychological correlates. Am J Geriatr Psychiatry 18, 1133-1140.

[4] Rossi A, Arduini L, Prosperini P, Kalyvoka A, Stratta P, Daneluzzo E (2000) Awareness of illness and outcome in schizophrenia. Eur Arch Psychiatry Clin Neurosci 250, 73-75.

[5] Jenkinson PM, Preston C, Ellis SJ (2011) Unawareness after stroke: A review and practical guide to understanding, assessing, and managing anosognosia for hemiplegia. J Clin Exp Neuropsychol 33, 1079-1093.

[6] O'Keeffe FM, Murray B, Coen RF, Dockree DM, Bellgrove MA, Garavan $\mathrm{H}$ et al. (2007) Loss of insight in frontotemporal dementia, corticobasal degeneration and progressive supranuclear palsy. Brain 130, 753-764.

[7] Turró-Garriga O, Conde-Sala JL, Reñé-Ramírez R, LópezPousa S, Gascón-Bayarri J, Garre-Olmo J (2014) Prevalence of anosognosia in Alzheimer disease. Med Clin (Barc) 143, 13-19.

[8] Markova IS, Berrios GE, Hodges JR (2004) Insight into memory function. Neurol Psychiatry Brain Res 11, 115-126.

[9] Rankin KP, Baldwin E, Pace-Savitsky C, Kramer JH, Miller BL (2005) Self-awareness and personality change in dementia. J Neurol Neurosurg Psychiatry 76, 632-639.

[10] Starkstein SE, Jorge R, Mizzahi R, Adrian J, Robinson RG (2007) Insight and danger in Alzheimer's disease. Eur $J$ Neurol 14, 455-460.

[11] Kashiwa Y, Kitabayashi Y, Narumoto J, Nakamura K, Ueda H, Fukui K (2005) Anosognosia in Alzheimer's disease: Association with patient characteristics, psychiatric symptoms and cognitive deficits. Psychiatry Clin Neurosci 59, 697-704. 
[12] Spalletta G, Girardi P, Caltagirone C, Orfei MD (2012) Anosognosia and neuropsychiatric symptoms and disorders in mild Alzheimer disease and mild cognitive impairment. J Alzheimers Dis 29, 761-772.

[13] Portellano-Ortiz C, Turró-Garriga O, Gascón-Bayarri J, Piñán-Hernández S, Moreno-Cordón L, Viñas-Díez V, Reñé-Ramírez R, Conde-Sala JL (2014) The influence of anosognosia and depression on the perceived quality of life of patients with Alzheimer's disease: A 12 months followup. Rev Neurol 59, 193-204.

[14] Starkstein SE, Chemerinski E, Sabe L, Kuzis G, Petracca G, Tesón A, Leiguarda R (1997) Prospective longitudinal study of depression and anosognosia in Alzheimer's disease. $\mathrm{Br} \mathrm{J}$ Psychiatry 171, 47-52.

[15] Starkstein SE, Jorge R, Mizrahi R, Robinson RG (2006) A diagnostic formulation for anosognosia in Alzheimer's disease. J Neurol Neurosurg Psychiatry 77, 719-725.

[16] Clare L, Goater T, Woods B (2006) Illness representations in early-stage dementia: A preliminary investigation. Int $J$ Geriatr Psychiatry 21, 761-767.

[17] Seltzer B, Vasterling JJ, Yoder J, Thompson KA (1997) Awareness of deficit in Alzheimer's disease: Relation to caregiver burden. Gerontologist 37, 20-24.

[18] Markova I, Berrios G (2001) The object of insight assessment: Relationship to the insight structure. Psychopathology 34, 245-252.

[19] Reed BR, Jagust WJ, Coulter L (1993) Anosognosia in Alzheimer's disease: Relationship to depression, cognitive function and cerebral perfusion. J Clin Exp Neuropsychol 2, 231-244.

[20] Conde-Sala JL, Reñé-Ramírez R, Turró-Garriga O, Gascón-Bayarri J, Juncadella-Puig M, Moreno-Cordón L, Viñas-Diez V, Garre-Olmo J (2013) Clinical differences in patients with Alzheimer's disease according to the presence or absence of anosognosia: Implications for perceived quality of life. J Alzheimers Dis 33, 1105-1116.

[21] Clare L, Whitaker CJ, Nelis SM, Martyr A, Markova IS, Roth I, Woods RT, Morris RG (2013) Self-concept in early stage dementia: Profile, course, correlates, predictors and implications for quality of life. Int J Geriatr Psychiatry 28, 494-503.

[22] Spalletta G, Piras F, Piras F, Sancesario G, Iorio M, Fratangeli C, Cacciari C, Caltagirone C, Orfei MD (2014) Neuroanatomical correlates of awareness of illness in patients with amnestic mild cognitive impairment who will or will not convert to Alzheimer's disease. Cortex 61, 183195.

[23] Starkstein SE (2014) Anosognosia in Alzheimer's disease. Cortex 61, 64-73.

[24] McKhann G, Drachman D, Folstein M, Katzman R, Price D, Stadlan EM (1984) Clinical diagnosis of Alzheimer's disease: Report of the NINCDS-ADRDA Work Group under the auspices of Department of Health and Human Services Task Force on Alzheimer's Disease. Neurology 34, 939-944.

[25] Folstein MF, Folstein SE, McHugh PR, "Mini Mental State" (1975) A practical method for grading the cognitive state of patients for the clinician. J Psychiatr Res 12, 189-198.

[26] Reisberg B, Ferris SH, De Leon MJ, Crook T (1982) The Global Deterioration Scale for assessment of primary degenerative dementia. Am J Psychiatry 139, 1136-1139.

[27] Migliorelli R, Tesón A, Sabe L, Petracca G, Petracchi M, Leiguarda R, Starkstein SE (1995) Anosognosia in Alzheimer's disease: A study of associated factors. $\mathrm{J} \mathrm{Neu}$ ropsychiatry Clin Neurosci 7, 338-344.
[28] Gelinas I, Gauthier L, McIntyre M, Gauthier S (1999) Development of a functional measure for persons with Alzheimer's disease: The disability assessment for dementia. Am J Occup Ther 53, 471-481.

[29] Cummings JL, Mega M, Gray K, Rosemberg-Thompson S, Carusi DA, Gornbein J (1994) The Neuropsychiatric inventory. Comprehensive assessment of psychopathology in dementia. Neurology 44, 2308-2314.

[30] Vilalta-Franch J, Lozano-Gallego M, Hernandez-Ferrandiz M, Llinás-Reglá J, López-Pousa S, López OL (1999) The Neuropsychiatric Inventory. Propiedades psicométricas de su adaptación al español. Rev Neurol 29, 15-19.

[31] Zarit S-H, Reever K-E, Bach-Peterson J (1980) Relatives of the impaired elderly. Correlates of feelings of burden. Gerontologist 20, 649-654.

[32] Aalten P, van Valen E, de Vugt ME, Lousberg R, Jolles J, Verhey FR (2006) Awareness and behavioral problems in dementia patients: A prospective study. Int Psychogeriatr 18, 3-17.

[33] Clare L, Wilson BA (2006) Longitudinal assessment of awareness in early-stage Alzheimer's disease using comparable questionnaire-based and performance-based measures: A prospective one-year follow-up study. Aging Ment Health 10, 156-165.

[34] Starkstein SE, Brockman S, Bruce D, Petracca G (2010) Anosognosia is a significant predictor of apathy in Alzheimer's disease. J Neuropsychiatry Clin Neurosci 22, 378-383.

[35] Clare L, Whitaker CJ, Nelis SM, Martyr A, Markova IS, Roth I, Woods RT, Morris RG (2013) Self-concept in early stage dementia: Profile, course, correlates, predictors and implications for quality of life. Int J Geriatr Psychiatry 28, 494-503.

[36] Scarmeas N, Albert SM, Manly JJ, Stern Y (2006) Education and rates of cognitive decline in incident Alzheimer's disease. J Neurol Neurosurg Psychiatric 77, 308-316.

[37] Spitznagel MB, Tremont G (2005) Cognitive reserve and anosognosia in questionable and mild dementia. Arch Clin Neuropsychol 20, 505-515.

[38] Lamar M, Lasarev MR, Libon DJ (2002) Determining levels of awareness in dementia research. J Neuropsychiatr Clin Neurosci 14, 430-437.

[39] Suchy Y, Krayabill ML, Franchow E (2011) Instrumental activities of daily living among community-dwelling older adults: Discrepancies between self-report and performance are mediated by cognitive reserve. J Clin Exp Neuropsychol 33, 92-100.

[40] Léger GC1, Banks SJ (2014) Neuropsychiatric symptom profile differs based on pathology in patients with clinically diagnosed behavioral variant frontotemporal dementia. Dement Geriatr Cogn Disord 37, 104-112.

[41] Salmon E (2010) Je ne suis pas fou. Etudes de l'anosognosie dans la maladie d'Alzheimer. Bull Mem Acad R Med Belg 165, 339-348.

[42] Shibata K, Narumoto J, Kitabayashi Y, Ushijima Y, Fukui K (2008) Correlation between anosognosia and regional cerebral blood flow in Alzheimer's disease. Neurosci Lett 435, 7-10.

[43] Verhulsdonk S, Quack R, Hoft B, Lange-Asschenfeldt C, Supprian T (2013) Anosognosia and depression in patients with Alzheimer's dementia. Arch Gerontol Geriatr 57, 282287.

[44] Mograbi DC, Brown R, Morris RG (2009) Anosognosia in Alzheimer's disease. The petrified self. Conscious Cogn 18, 989-1003. 
[45] Conde-Sala JL, Turró-Garriga O, Piñán-Hernández S, Portellano-Ortiz C, Viñ;as-Diez V, Gascón-Bayarri J, Reñé-Ramírez R (2016) Effects of anosognosia and neuropsychiatric symptoms on the quality of life of patients with Alzheimer's disease: A 24-month follow-up study. Int J Geriatr Psychiatry 31(2), 109-119.

[46] Conde-Sala JL, Reñé-Ramírez R, Turró-Garriga O, Gascón-Bayarri J, Juncadella-Puig M, Moreno-Cordón L, Viñas-Diez V, Vilalta-Franch J, Garre-Olmo J (2013) Factors associated with the variability in caregiver assessments of the capacities of patients with Alzheimer disease. J Geriatr Psychiatr Neurol 26, 86-94.

[47] Mograbi DC, Ferri CP, Sosa AL, Stewart R, Lacks J, Brown R, Morris RG (2012) Unawareness of memory impairment in dementia: A population-based study. Int Psychogeriatr 24, 931-939.

[48] Turró-Garriga O, Garre-Olmo J, Vilalta-Franch J, CondeSala JL, de Gracia-Blanco M, López-Pousa S (2013) Burden associated with the presence of anosognosia in Alzheimer's disease. Int J Geriatr Psychiatry 28, 291-297. 